\title{
Cellulose Nanocrystal Membranes as Excipients for Drug Delivery Systems
}

\author{
Ananda M. Barbosa ${ }^{1,2}$, Eduardo Robles ${ }^{2}$, Juliana S. Ribeiro ${ }^{3}$, Rafael G. Lund ${ }^{3}$, \\ Neftali L. V. Carreño ${ }^{1}$ and Jalel Labidi ${ }^{2, *}$ \\ 1 Postgraduated Program in Science and Material Engineering, Technology Development Center, \\ Federal University of Pelotas, Gomes Carneiro 1, Pelotas-RS 96010-610, Brazil; \\ ananda.barbosa@ufpel.edu.br (A.M.B.); neftali@ufpel.edu.br (N.L.V.C.) \\ 2 Chemical \& Environmental Engineering Department, University of the Basque Country UPV/EHU, \\ Plaza Europa 1, Donostia-San Sebastian 20018, Spain; jerobles001@ehu.eus \\ 3 Postgraduate Program in Dentistry, Federal University of Pelotas, Gonçalves Chaves 457, \\ Pelotas-RS 96015-560, Brazil; julianar.fo@ufpel.edu.br (J.S.R.); rglund@ufpel.edu.br (R.G.L.) \\ * Correspondence: jalel.labidi@ehu.eus; Tel.: +34-943-017-178
}

Academic Editor: Tommaso Carofiglio

Received: 30 October 2016; Accepted: 2 December 2016; Published: 12 December 2016

\begin{abstract}
In this work, cellulose nanocrystals (CNCs) were obtained from flax fibers by an acid hydrolysis assisted by sonochemistry in order to reduce reaction times. The cavitation inducted during hydrolysis resulted in CNC with uniform shapes, and thus further pretreatments into the cellulose are not required. The obtained CNC exhibited a homogeneous morphology and high crystallinity, as well as typical values for surface charge. Additionally, CNC membranes were developed from CNC solution to evaluation as a drug delivery system by the incorporation of a model drug. The drug delivery studies were carried out using chlorhexidine (CHX) as a drug and the antimicrobial efficiency of the CNC membrane loaded with CHX was examined against Gram-positive bacteria Staphylococcus aureus (S. Aureus). The release of CHX from the CNC membranes is determined by UV-Vis. The obtaining methodology of the membranes proved to be simple, and these early studies showed a potential use in antibiotic drug delivery systems due to the release kinetics and the satisfactory antimicrobial activity.
\end{abstract}

Keywords: cellulose nanocrystals; chlorhexidine; Staphylococcus aureus

\section{Introduction}

Flax is a temperate-climate erected plant of the Linaceae family with usually $1 \mathrm{~m}$ height [1]; flax fibers have been used for thousands of years to make different textile products because of their good performance [2]. Nowadays, flax has been studied like raw material for high value-added nanostructured cellulose production [3].

Cellulose nanocrystals (CNCs) correspond to the ordered crystalline components that can be extracted from various cellulosic materials. The extraction of CNCs from fibers usually consists of an acid-induced de-structuring process during which heterogeneous acid hydrolysis involves the diffusion of acid molecules into cellulose fibers, followed by cleavage of glycosidic bonds. This acid hydrolysis step is followed by several cycles of centrifugation, after which dialysis is performed to reach neutral $\mathrm{pH}$ and ultrasonication to redisperse CNC in a colloidal water suspension [4-6]. Approaches to optimize this methodology have been described [4,5,7].

Properties such as biodegradability, bio-based, and biocompatibility make cellulose an important and fascinating polymer for many applications [8]. Therefore, functional materials can be developed. Recent studies address the cellulose as excipient for drug delivery systems [9-11]. The application of CNCs proves to be an alternative that deserves further clarification [12]. 
This work is aimed to analyze CNCs obtained by high frequency cavitation-inducted acid hydrolysis in order to obtain a different particle with high quality in a shorter period of time than normally used in the conventional hydrolysis and without catalyst or pretreatments and apply the obtained material as a membrane for drug delivery. Different characterizations were performed to assess the CNC and to analyze the colloid solution and the solid-state.

Furthermore, CNC membranes were developed with the addition of chlorhexidine (CNC-CHX membrane). $\mathrm{CHX}$ has broad antiseptic properties against a wide variety of Gram-negative and Gram-positive organisms because the positively charged parts of the CHX molecule react with the phosphate groups of lipopolysaccharides in the bacterial cell wall causing the antimicrobial activity of CHX [13].

CNC-CHX membranes had the antibacterial activities investigated using Gram-positive (G+) bacteria S. aureus. S. aureus was chosen because this human pathogen can cause problems from skin infections to life-threatening health conditions [14]. The effects of different CHX dosages on the antibacterial activity of the nanocomposites were investigated.

\section{Experimental Procedure}

\subsection{Materials}

Flax (Linus usitatisimum) was kindly provided by Artic Fiber Company Ltd. (Kiiminki, Finland), and sulfuric acid was provided by Panreac ${ }^{\circledR}$ (Barcelona, Spain). All other components were used at laboratory conditions and provided by Sigma-Aldrich Spain (Madrid, Spain).

\subsection{Cavitation-Induced Acid Hydrolysis}

Flax fiber delignification was performed as described by Robles et al. [15]. Acid hydrolysis was performed for the bleached cellulose without pretreatments using a $10.2 \mathrm{M}$ solution of $\mathrm{H}_{2} \mathrm{SO}_{4}$ $(1: 20 \mathrm{w} / \mathrm{v})$ at two different temperatures $\left(50\right.$ and $\left.60^{\circ} \mathrm{C}\right)$ inside an Elmasonic Elma S $70 \mathrm{H}$ sonication bath, where cavitations were induced at $37 \mathrm{kHz}$, and time was varied from 30,45 and $60 \mathrm{~min}$. All reactions were stopped with cold distilled water $(1: 3 \mathrm{v} / \mathrm{v})$, non-hydrolyzed fraction was separated with a glass funnel and the filtered fraction was centrifuged three times at $8000 \mathrm{rpm}$ for $10 \mathrm{~min}$ and then dialyzed to distilled water until neutral $\mathrm{pH}$ was stabilized for further analysis.

\subsection{Membrane Production}

Three different concentrations of CHX were used to produce the membranes. The fraction of CHX $(0.015 \mathrm{~g}, 0.0015 \mathrm{~g}$ or $0.00015 \mathrm{~g})$ was dissolved into an appropriate solvent, and then $10 \mathrm{~mL}$ of nanocrystal solution was added for each fraction of CHX (selected nanocrystal suspension corresponds to $50{ }^{\circ} \mathrm{C} / 45 \mathrm{~min}$ conditions described in Section 2.2), and this mixture continued being stirred and heated at $50^{\circ} \mathrm{C}$ for $3 \mathrm{~h}$. Finally, the suspension was poured into aluminum dishes and put into an oven at $50^{\circ} \mathrm{C}$ for $20 \mathrm{~h}$.

\subsection{Characterization}

\subsubsection{Raw Material Chemical Composition}

Chemical analysis of the flax fibers was performed to determine the amount of cellulose available for further extraction. This characterization was carried out according to the Technical Association of the Pulp and Paper Industry (TAPPI) standard methods.

\subsubsection{Infrared Spectroscopy (FTIR-ATR)}

Infrared spectra were recorded on a Spectrum Two FT-IR Spectrometer manufactured by Perkin Elmer, Inc. (London, UK) equipped with a Universal Attenuated Total Reflectance accessory with 
an internal reflection diamond crystal lens. The defined range was from 800 to $4000 \mathrm{~cm}^{-1}$ and the resolution $8 \mathrm{~cm}^{-1}$. For each sample, 10 scans were recorded.

\subsubsection{Gravimetric Analysis}

Cellulose nanocrystals were dry measured to control the yield of each treatment after hydrolysis by using the following equation:

$$
\mathrm{Y}=\mathrm{M}_{\mathrm{C}} \cdot \mathrm{M}_{\mathrm{T}} / \mathrm{M}_{\mathrm{S}} \cdot \mathrm{M}_{\mathrm{O}}
$$

where $\mathrm{M}_{\mathrm{C}}$ is the mass of dried cellulose nanocrystals (10-15 $\min$ in an oven at $\left.105^{\circ} \mathrm{C}\right) ; \mathrm{M}_{\mathrm{T}}$ is the mass of the total suspension, $\mathrm{M}_{\mathrm{S}}$ is the mass of the suspension sample before drying; and $\mathrm{M}_{\mathrm{O}}$ is the cellulose mass before hydrolysis.

\subsubsection{Size Measurement and Zeta Potential}

Particle size and zeta potential were measured inside Malvern Z Nanosizer Equipment (Worcestershire, UK), refractive index for cellulose was considered at 1.47, and measurements were performed at $25^{\circ} \mathrm{C}$. For size analysis, $0.1 \mathrm{~g} \cdot \mathrm{L}^{-1}$ of cellulose suspension was put inside a disposable plastic cuvette performing 13 scans with an incidence angle of $173^{\circ}$ repeated three times for each sample. For zeta potential, nanocrystal suspensions were put inside Malvern folded capillary zeta cells and measured using the Smoluchowsky model $(\kappa \bullet a=1.50)$. Ten scans were performed, and three specimens of each sample were measured [16].

\subsubsection{Nuclear Magnetic Resonance (NMR)}

The ${ }^{13} \mathrm{C} C \mathrm{CP} / \mathrm{MAS}$ NMR spectrometry was performed using a Bruker $500 \mathrm{MHz}$ spectrometer (Karlsruhe, Germany) at a frequency of $250 \mathrm{MHz}$ with an acquisition time of $0.011 \mathrm{~s}$ at room temperature. The spectrum was recorded over 32 scans, and water was used as a solvent for all of the nanocrystalline celluloses.

\subsubsection{X-ray Diffraction (XRD)}

X-ray powder diffraction was measured to compare crystallinity achieved after each hydrolysis. Patterns were collected with a Panalytical Philips X'Pert PRO multipurpose diffractometer (Almelo, The Netherlands), with samples mounted on a zero background silicon wafer fixed in a generic sample holder, using monochromatic $\mathrm{CuK} \alpha$ radiation $\left(\lambda=1.5418 \AA\right.$ ) , $2 \theta$ Bragg angle between 5 and $50^{\circ}$, step size of $0.026^{\circ}$ and time per step of $80 \mathrm{~s}$ at room temperature. Crystalline contributions to the main signal were determined with the intensity observed at the traditional crystalline peaks: -110 , 110, 200 and 004, while the amorphous contribution that is attributed to the broad signal observed at $2 \theta \approx 18^{\circ}$ [17]. Different approaches to estimate the crystallinity used first consisted of the traditional Segal method [18] expressed in Equation (2):

$$
\text { CrI = 100(I_200/I_200 + I_am). }
$$

The Segal method is not the most accurate method to determine cellulose crystallinity, but as it is the most widely used, it can be useful to compare results from this study to those made in the past [19-21]. As a second and more precise method, Voigt functions were used to deconvolute peaks and determine the integrated surface corresponding to the peaks of 1-10, 110 and 200 Miller indices. Apparent crystallinity was estimated with the following equation:

$$
\mathrm{CrI}=100\left(\mathrm{~A}_{1-10}+\mathrm{A}_{110}+\mathrm{A}_{200}\right) /\left(\mathrm{A}_{\mathrm{tot}}\right)
$$

in which $\mathrm{A}_{1-10}+\mathrm{A}_{110}+\mathrm{A}_{200}$ corresponds to the area of the crystalline region and $\mathrm{A}_{\text {tot }}$ corresponds to the total area $[22,23]$. Crystallite size was estimated with the Scherrer equation using the peak corresponding to the 200 plane as seen in Equation (4): 


$$
\mathrm{d}_{200}=\kappa \lambda / \mathrm{H}_{200} \cdot \cos \theta,
$$

with $\kappa$ being the Scherrer constant most adjusted to the nanocrystal shape (0.86), $\lambda$ the wavelength $(1.5418 \AA), \mathrm{H}_{200}$ corresponds to the full width at half maximum intensity (FWHM) and $\theta$ is half the Bragg angle at peak maximum given in radians [24,25].

\subsubsection{Atomic Force Microscopy (AFM)}

Atomic force microscopy images were obtained operating in tapping mode with a NanoScope IIIa, Multimode TM-AFM from Digital Instruments-Veeco scanning probe microscope (Plainview, NY, USA) equipped with an integrated silicon tip cantilever with a resonance frequency of $300 \mathrm{kHz}$. To obtain representative results, different regions of the samples were scanned.

\subsubsection{Release Study}

The absorbance of the sampled medium was measured using a UV-Vis V-630 spectrophotometer (Jasco Inc. (Tokyo, Japan)). Firstly, an initial scanning was performed to determine the wavelength at which the readings would be carried out and the length of wavelength of $360 \mathrm{~nm}$ as selected. Then, various dilutions were performed obtaining several different concentrations. These solutions of different concentrations were then taken to the UV spectrophotometer at wavelength $360 \mathrm{~nm}$, the absorbance of the solutions at various concentrations was then determined, and then the calibration curve was developed. The drug loaded membranes were weighed ( $0.0030 \mathrm{~g}$ for each sample) and put in a glass vessel containing $10 \mathrm{~mL}$ of Phosphate-buffered saline (PBS) buffer solution (pH 7) and the analysis was performed every half hour for four hours, and then readings were taken at 24 and $48 \mathrm{~h}$. The experiments were conducted in duplicate.

\subsubsection{Antibacterial Activity}

\section{Characterization of the Standard Drug}

To characterize the chlorhexidine, the minimum inhibitory concentration (MIC) and minimum bactericidal concentration (MBC) were carried out by using broth microdilution techniques as described by the Clinical and Laboratory Standards Institute (M11-A8) with few modifications.

\section{Inoculum}

S. aureus ATCC 19095 cultivars were individually grown overnight in aerobic conditions at $37^{\circ} \mathrm{C}$ on Brain and Heart Infusion Agar (BHI), supplemented with $10 \%$ sucrose, for $24 \mathrm{~h}$. Colonies of microorganisms were then suspended in Brain and Heart Infusion broth for S. aureus, in order to make a suspension of $3 \times 108 \mathrm{CFU} \mathrm{mL}{ }^{-1}$. The microbial cell turbidity was then adjusted by spectrophotometry (spectrophotometer, Quimis, Brazil) at $405 \mathrm{~nm}$.

\section{Determination of MIC}

The stock solution of chlorhexidine was prepared in a dimethyl sulfoxide (DMSO) solution at a concentration of $500 \mu \mathrm{g} \cdot \mathrm{mL}^{-1}$. Chlorhexidine powder was previously weighed and dissolved in DMSO at $500 \mu \mathrm{g} \cdot \mathrm{mL}^{-1}$ concentration. The solutions were diluted in Muller Hinton medium, and the final drug concentrations ranged from 0.97 to $500 \mu \mathrm{g} \cdot \mathrm{mL}^{-1}$. In addition, $100 \mu \mathrm{L}$ of the inoculum suspension along with $100 \mu \mathrm{L}$ of the final product were added to the microculture plate wells. In the negative control, $100 \mu \mathrm{L}$ of microorganism solution plus $100 \mu \mathrm{L}$ of Muller Hinton medium was added, and $100 \mu \mathrm{L}$ of Muller Hinton medium and $100 \mu \mathrm{L}$ of the final product were added in the positive control. Three replicates were made for each concentration.

After $24 \mathrm{~h}$ of incubation at $35^{\circ} \mathrm{C}$, the absorbance of each well was read on a microplate reader (Thermo Plate TP-Reader, Thermo Fisher Scientific, Waltham, MA, USA) at a wavelength of $492 \mathrm{~nm}$. 
After the well had been agitated, MIC endpoints were determined as the first concentration of the antibacterial agent at which turbidity in the well was $\geq 50 \%$ less than that in the control well [26].

The measurement for their antibacterial activity, expressed as the percentage of activity (\% AE), was calculated with an adaptation from Felício et al. [27] according to Equation (5):

$$
\% \mathrm{AE}=100-(\mathrm{AE}-\mathrm{AEB} / \mathrm{AC}-\mathrm{ACB}) \times 100,
$$

where AE represents the absorbance of the test plates after the incubation time; AEB is the absorbance of plates containing medium, sample and inoculum at $t=0$ of incubation; $A C$ is the absorbance of plates containing negative control (without vehicle) (100\% of inoculum growth); and ACB is the absorbance of plates containing culture medium. All of the MIC values were calculated by nonlinear regression.

\section{Determination of $\mathrm{MBC}$}

Each inoculum from the previous test that did not show growth was subcultured on agar plates. After $24 \mathrm{~h}$ of incubation, the reading was determined by the visible growth of strains. The CBM was considered to be the first concentration of the antibacterial agent at which turbidity in the well was $\geq 50 \%$ less than that in the control well.

Antibacterial Activity of the Drug Delivery System

Modified direct contact test was used to evaluate the antimicrobial effect. The modified direct contact test (mDCT) consists of the measurement of cinematic microbial growth by close contact between the micro-organism tested and the material [28] by using microplate 96-well cell cultures. Previously, the samples were sterilized by Gamma radiation into an Eldorado-78 equipment (Atomic Energy of Canada Ltd. (Chalk River, ON, Canada)). After sterilization, the specimens were placed in 96-well plates, with $n=6$ for each group tested.

Bacterial Strains and Culture Conditions

Staphylococcus aureus ATCC 19095 were individually grown overnight in aerobic conditions at $37^{\circ} \mathrm{C}$ on Brain and Heart Infusion Agar (BHI) supplemented with $10 \%$ sucrose for 24 h. Colonies of microorganisms were then suspended in Brain and Heart Infusion broth for S. aureus, in order to make a suspension of $3 \times 10^{8} \mathrm{CFU} \mathrm{mL} \mathrm{mL}^{-1}$. The microbial cell turbidity was adjusted by spectrophotometry (spectrophotometer, Quimis, Brazil) at $405 \mathrm{~nm}$. From this inoculum was added $20 \mu \mathrm{L}$ of bacterial suspension into each well to be evaluated.

The materials were placed in microplate wells with the aid of sterile forceps being a specimen in each well, and the material was inoculated with $20 \mu \mathrm{L}$ of microbial suspension (S. aureus $+\mathrm{BHI}+$ sucralose). The discs were incubated for 1 or $24 \mathrm{~h}$ at $37^{\circ} \mathrm{C}$ and approximately $100 \%$ relative humidity. Microplate wells containing the same volume of bacterial suspension without test discs were also incubated as controls.

Afterwards, $180 \mu \mathrm{L}$ of culture medium (BHI, Guangzhou Mecan Trading Co., Ltd., Guangzhou, China) was added into each well and shaken for $10 \mathrm{~min}$. In addition, $100 \mu \mathrm{L}$ of bacterial suspension from each well was transferred for dilution. Serial dilutions and platings were carried out in disposable Petri dishes containing BHI agar divided into eight parts. Each plate received two drops of $20 \mu \mathrm{L}$ per dilution and was incubated at $37^{\circ} \mathrm{C}$ for $24 \mathrm{~h}$. Beyond the period of incubation, the concentration of colony forming units $\left(\mathrm{CFU} \mathrm{mL} \mathrm{m}^{-1}\right)$ was counted.

\section{Results and Discussion}

\subsection{Raw Material Chemical Composition}

Table 1 presents the chemical composition of flax fibers analyzed with standard methods as the mean of six tests for each standard, as well as a comparison to other previously published works in 
which flax fibers were used. A high content of cellulose was observed making flax a reliable source for cellulose nanocrystal extraction. The high amount of hemicelluloses present in this fibers makes it desirable to perform an alkali stage in the cellulose extraction sequence, while low lignin content allows for a less aggressive bleaching stage (hydrogen peroxide) to finally extract cellulose with high purity.

Table 1. Chemical composition of the raw material used in this study compared to other sources.

\begin{tabular}{cccc}
\hline Extractives & Lignin & Hemicelluloses & $\alpha$-Cellulose \\
\hline $2.58 \pm 2.11^{\mathrm{a}}$ & $1.70 \pm 0.31^{\mathrm{a}}$ & $15.42 \pm 0.53^{\mathrm{a}}$ & $63.91 \pm 1^{\mathrm{a}}$ \\
$1.70^{\mathrm{c}}$ & $24.90^{\mathrm{b}}$ & $13.70^{\mathrm{b}}$ & $73.80^{\mathrm{b}}$ \\
- & $2.8 \pm 0.50^{\mathrm{c}}$ & $8.7 \pm 0.20^{\mathrm{c}}$ & $77 \pm 0.30^{\mathrm{c}}$ \\
- & $4.70^{\mathrm{d}}$ & $12.90^{\mathrm{d}}$ & $68.70^{\mathrm{d}}$ \\
\hline \multicolumn{4}{c}{$\mathrm{a}$ (his study); ${ }^{\mathrm{b}}[29]^{\mathrm{c}}[6]^{\mathrm{d}}\left[{ }^{\mathrm{d}}[30]\right.}$.
\end{tabular}

\subsection{FTIR-ATR Spectroscopic Analysis}

Flax fibers were received untreated and were pulped and bleached in an integrated Elemental Chlorine Free sequence. In Figure 1A, it is possible to follow the appearance of the flax during the different steps of the treatment. Figure 1B shows the FT-IR spectra of flax fibers as received and flax cellulose fibers. Compared to flax fibers, flax cellulose fibers present more defined peaks and bands that are characteristic to cellulose and can be seen as follows: the band between 3600 and $3000 \mathrm{~cm}^{-1}$ corresponds to stretching vibrations of hydroxyl groups in cellulose, and the band between 3000 and $2600 \mathrm{~cm}^{-1}$ and $2860 \mathrm{~cm}^{-1}$ corresponds to $-\mathrm{CH}$ groups, respectively. The signal of $2920 \mathrm{~cm}^{-1}$ corresponds to the $\mathrm{CH}_{3}$ group and the signal of $2860 \mathrm{~cm}^{-1}$ corresponds to the $\mathrm{CH}_{2}$ group. The peak at $1645 \mathrm{~cm}^{-1}$ can be attributed to the bending mode of the absorbed water in carbohydrates. The band at $1420 \mathrm{~cm}^{-1}$ corresponds to $\mathrm{CH}_{2}$ bending and the one at $1215 \mathrm{~cm}^{-1}$ is originated from the $-\mathrm{OH}$ in plane-bending cellulose [31]. The adsorption band at $1150 \mathrm{~cm}^{-1}$ can be attributed to $\mathrm{C}-\mathrm{O}$ antisymmetric bridge stretching. Finally, the peak at $890 \mathrm{~cm}^{-1}$ is characteristic of $\beta$-glycosidic linkages between glucose units [32].


Figure 1. Bleaching sequence diagrams (A) along with the corresponding infrared spectrum (B).

\subsection{Colloid Solution Analysis}

To evaluate colloidal stability of the cellulose nanocrystals, $1 \mathrm{wt} \%$ solutions were prepared for each sample, and they were vortexed for a minute and photographed to evaluate initial conditions; solutions were left to rest for 21 days, after which another picture was made (Figure 2). Samples showed different stabilities as colloidal suspensions after the final time elapsed. Anisotropic sedimentation was observed in samples elaborated with lower temperature, while those with higher temperatures 
had stronger isotropic phases. Regarding sonication time, it is clear that after longer sonication time, particles maintain isotropic dispersion in the water suspension, as the effect of the sulfuric acid after longer time generates a more charged surface of the nanocrystals that acts as a repulsive force maintaining nanocrystals suspended in polar liquids [33].

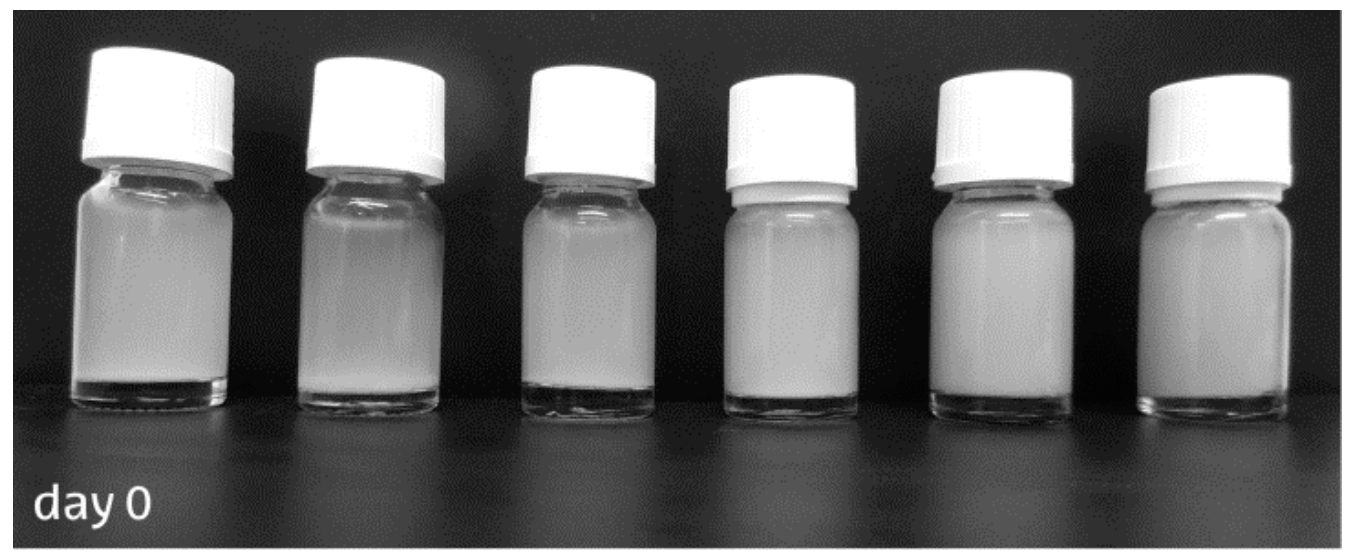

(a)

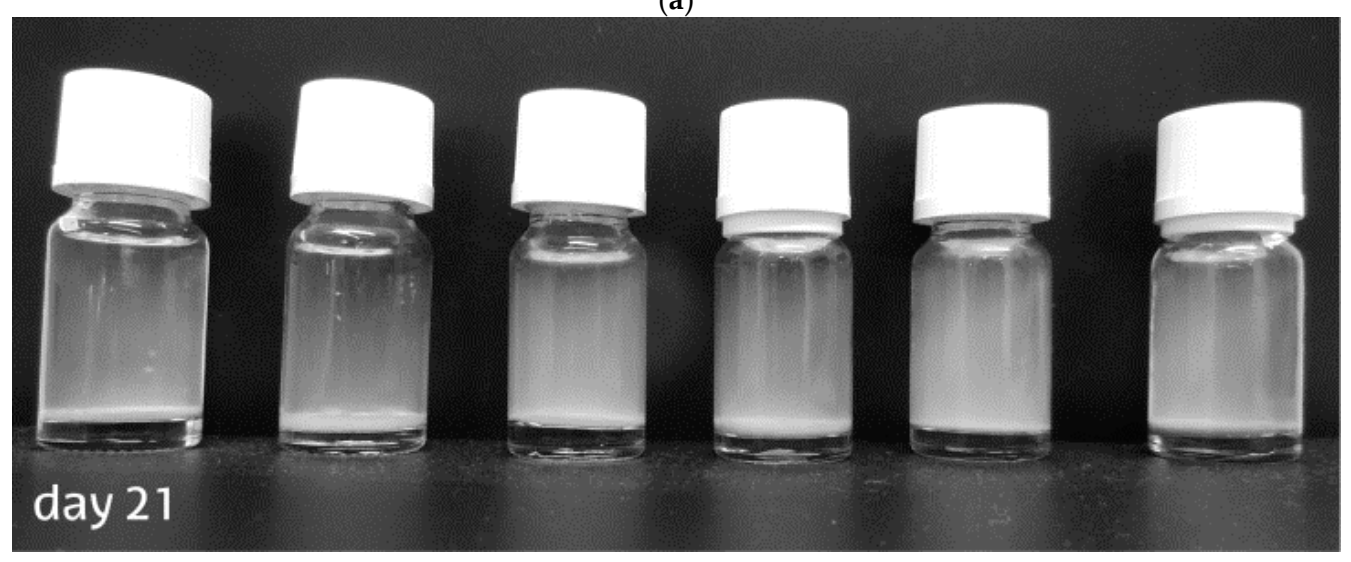

(b)

Figure 2. Pictures of the differently obtained cellulose nanocrystals in 1 wt \% aqueous suspension before (a) and after 21 days of settlement (b). (From left to right, 50-30; 50-45; 50-60; 60-30; 60-45; 60-60).

\subsection{Nuclear Magnetic Resonance (NMR) Analysis}

Figure 3 shows the NMR spectra of the CNCs after different hydrolysis conditions, and the main signals between 110 and 55 ppm correspond to crystalline cellulose I [34] and are attributed to carbons in a hydroglucose units listed from $C_{1}$ to $C_{6}$. Differences observed between the $C N C$ are attributed to the differences in the supramolecular structure or the polymer chain packing of the samples, which may be affected during the hydrolysis, and slight variations can be observed in $C_{1}$ for 60-30 and 60-60 samples, with their peaks presenting sharper points in the region closer to $C_{4}$, which is attributed to cellulose I $\beta$; on the other hand, 50-30, 50-45 and 60-45 celluloses present more rounded peaks for $C_{1}$, which implies a mayor presence of paracrystalline cellulose. In $C_{4}$ for the 60-60 sample, it can be appreciated that the excess of hydrolysis may have disintegrated polymeric chains to main glucose units, thus showing an increment in the amorphous region of $\mathrm{C}_{4}$ carbon. 


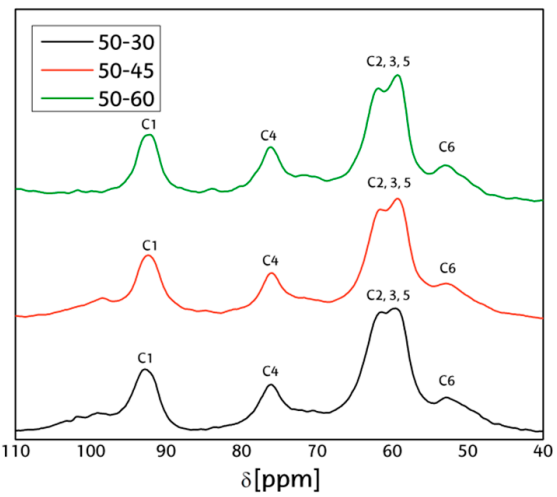

(a)

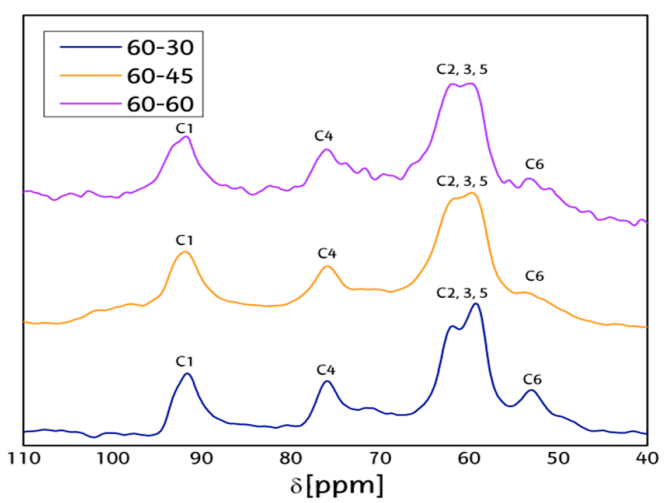

(b)

Figure 3. NMR spectra of cellulose nanocrystals after different hydrolysis conditions. (a) 50-30 (black), 50-45 (red) and 50-60 (green); (b) 60-30 (blue), 60-45 (orange) and 60-60 (violet).

\subsection{Size Measurement}

In Figure 4, the histograms of the size distribution of each obtained nanocrystal are presented, 60-60 CNCs present the highest homogeneity, as almost 70\% of them are contained in the $40-50 \mathrm{~nm}$ range, while 50-30 and 50-60 present more even dispersions. The higher percent of CNCs under the $60 \mathrm{~nm}$ limit that can be seen in 50-30 can be due to low hydrolysis during the reaction as they have the slowest yield (Table 2), meaning that most of the fibers were not hydrolyzed during the reaction. In addition, 50-45 and 60-45 also present higher homogeneity in their size distribution, as more than half of their counts are in the same range, being $50-60 \mathrm{~nm}$ for $50-45$ and $40-50 \mathrm{~nm}$ for 60-45. These two samples also presented higher yields in general, and CNC yields maintain a close correlation depending on the temperature and time used for the reaction, with the 60-60 treatment being an exception, as it presents smaller particles but also lower yield. This can be due to cellulose polysaccharide chain degradation to single glucose chains.

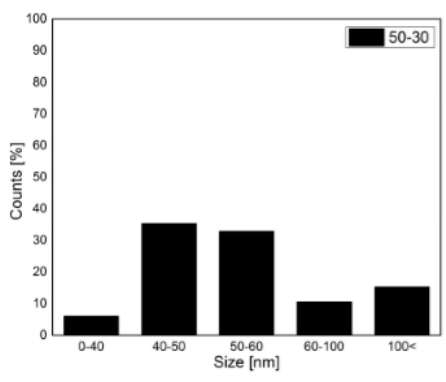

(a)

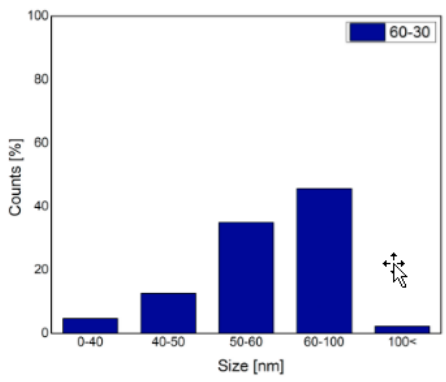

(d)

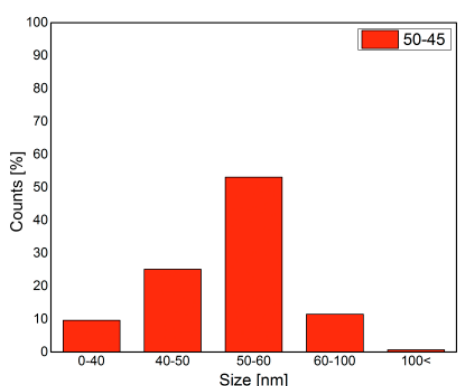

(b)

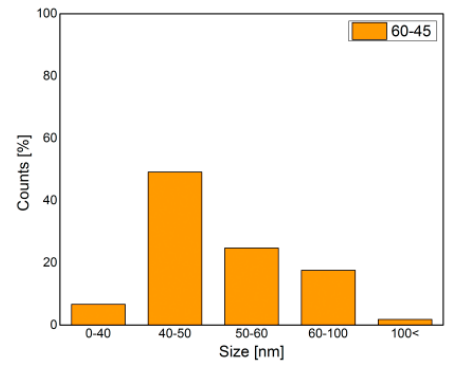

(e)

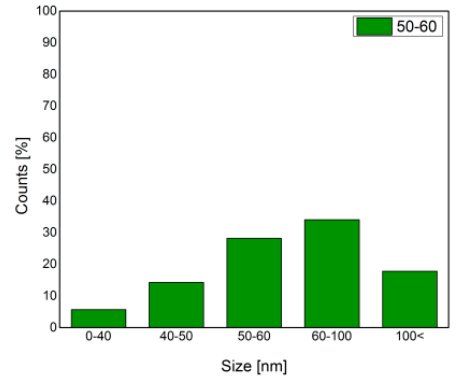

(c)

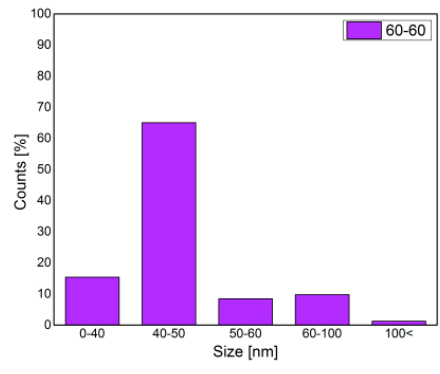

(f)

Figure 4. Size histograms of the elaborated CNCs. (a) 50-30; (b) 50-45; (c) 50-60; (d) 60-30; (e) 60-45; (f) $60-60$. 


\subsection{Yield and Zeta Potential}

As a way to analyze the effectiveness of each treatment performed to obtain cellulose nanocrystals, all of the samples were filtered with a glass Buchner funnel with a sintered glass filter No. 1 to retain un-hydrolyzed fibers before centrifugation; therefore, homogeneous cellulose nanocrystal suspensions were obtained, with the removal of larger particles through filtration and the undesirable particles with the centrifugation, and yields were measured gravimetrically and results are shown in Table 2 as well as the zeta potential and the Scherrer approximated. Regarding zeta potential, all of the hydrolyzed nanocrystals showed surface charges in the range characteristic of such particles with only 50-30 and 60-60 being within the moderate range ( \pm 30 to $\pm 40 \mathrm{mV}$ ), while the rest is in the incipient stability range ( \pm 10 to $\pm 30 \mathrm{mV}$ ) with no significant variations between them.

Table 2. Crystallinity properties of the different nanocrystals.

\begin{tabular}{|c|c|c|c|c|c|}
\hline \multirow[b]{2}{*}{ Sample/Method } & \multicolumn{2}{|c|}{ Crystallinity Index (\%) } & \multirow[b]{2}{*}{ Yield (g/g) } & \multirow[b]{2}{*}{ Zeta Potential (mV) } & \multirow{2}{*}{$\begin{array}{c}\delta_{200}(\AA) \\
\text { Scherrer } \\
\text { Approximated }\end{array}$} \\
\hline & $\begin{array}{c}\text { Segal } \\
\text { Method }\end{array}$ & $\begin{array}{l}\text { Deconvolution } \\
\text { Method }\end{array}$ & & & \\
\hline $50-30$ & 86.17 & 80.19 & 0.0930 & -32.70 & 54.39 \\
\hline $50-45$ & 90.50 & 85.55 & 0.1799 & -24.30 & 51.91 \\
\hline $50-60$ & 91.63 & 91.23 & 0.4032 & -24.33 & 50.68 \\
\hline $60-30$ & 90.82 & 85.88 & 0.0656 & -26.57 & 53.40 \\
\hline $60-45$ & 90.89 & 87.93 & 0.1415 & -25.40 & 54.95 \\
\hline $60-60$ & 90.90 & 83.69 & 0.0808 & -31.35 & 50.01 \\
\hline
\end{tabular}

\subsection{X-ray Diffraction (XRD)}

Figure 5 shows the scattered raw powder diffraction patterns, the position of the peak associated by the Segal method to main crystalline contribution, and the correspondences to the crystalline plane with Miller index (200) as marked, as well as the point associated with the amorphous contribution to the signal. While the intensity of the (200) plane is more or less the same in all cases, the one attributed to the amorphous region presents a constant decrease at longer reaction times.

To determine the position of signals generated by the cellulose nanocrystals and gather more information about their composition, powder diffraction patterns were simulated with PeakFit 4.12 software by Systat Software, Inc. (San Jose, CA, USA) to fit the original pattern $\left(R^{2} \geq 0.998\right)$ and then deconvoluted using Voigt curves. All patterns correspond to those of native cellulose (cellulose I $\alpha$ and $\mathrm{I} \beta$ ) with stronger contributions attributed to cellulose $\mathrm{I} \beta$.

Cellulose crystallinity has been extensively evaluated by the Segal method, although this method is now considered imprecise and obsolete for quantitative analysis, and it is still used by many researchers around the world and therefore still represents an option for fast qualitative analysis, as it can be easily obtained and there is a larger amount of bibliographic references to compare with $[20,35]$. On the other hand, the integrated area method has been gathering more attention as it can represent a more realistic approach to analyze the crystalline domains that are present in the cellulose nanocrystals after the extraction of non-crystalline regions [22]. Table 2 presents the crystallinity index corresponding to Segal and integral area methods as well as the size approximation of the (200) crystalline region as proposed by Scherrer for qualitative purposes. In general, a high crystallinity can be observed for all obtained nanocrystals, with a constant increase in cellulose crystallinity, as reaction time is longer for $\mathrm{CNC}$ obtained at $50^{\circ} \mathrm{C}$. In both Segal and deconvolution methods, the change in crystallinity for samples treated at $60^{\circ} \mathrm{C}$ is very low, and when time elapses up to $60 \mathrm{~min}$, it decreases, showing a possible de-crystallization of the cellulose nanocrystals. Crystallite size approximated by Scherrer equation $\left(\delta_{200}\right)$ does not vary significantly between the different treatments used and are within the range of other reported data $[15,36]$. 

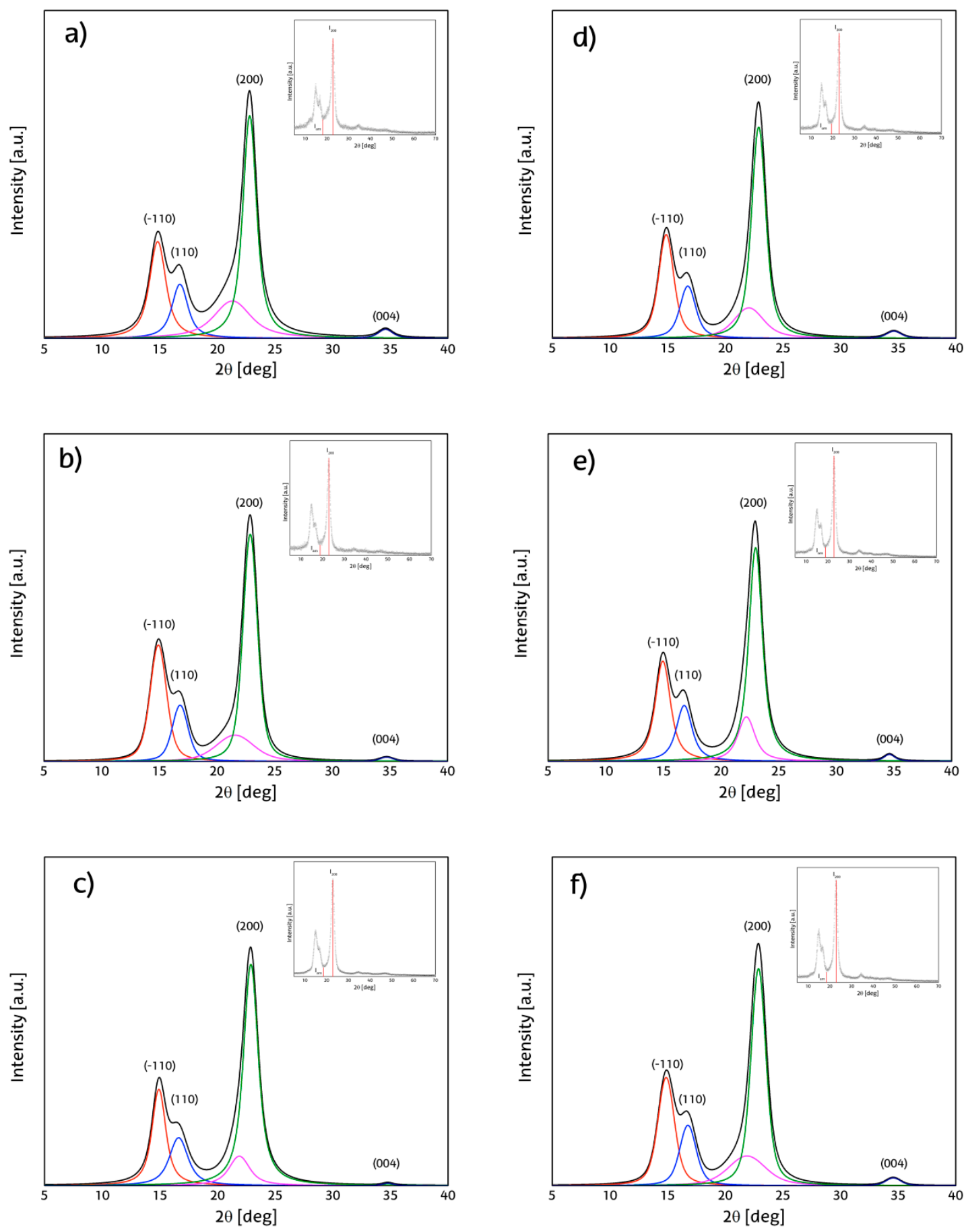

Figure 5. Raw and simulated powder diffraction patterns for: (a) 50-30; (b) 50-45; (c) 50-60; (d) 60-30; (e) 60-45 and (f) 60-60.

\subsection{Atomic Force Microscopy (AFM)}

The obtained nanocrystals present in all cases rod-like morphology characteristics of cellulose nanocrystals and homogeneous size in general (Figure 6), with significant variances depending on the method selected for their obtention. Nanocrystals obtained by methods involving higher temperatures (60-30, 60-45 and 60-60) present smaller particles in both length and width, with 60-60 having the smallest dimensions and 50-60 the largest. In the case of 50-30 nanocrystals, a larger aspect ratio can be observed in atomic force microscopy. 


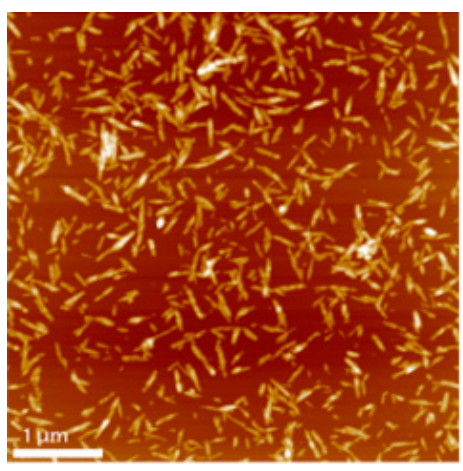

(a)

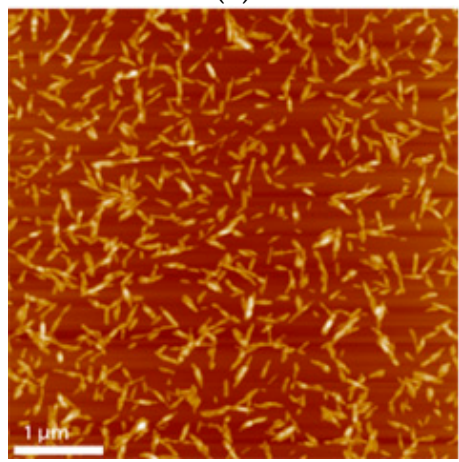

(d)

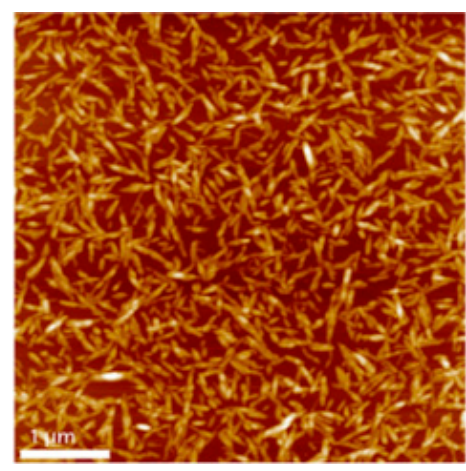

(b)

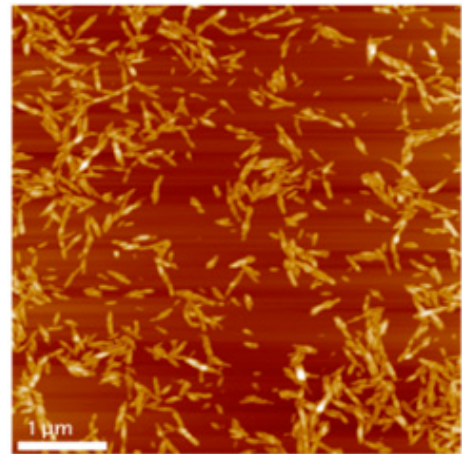

(e)

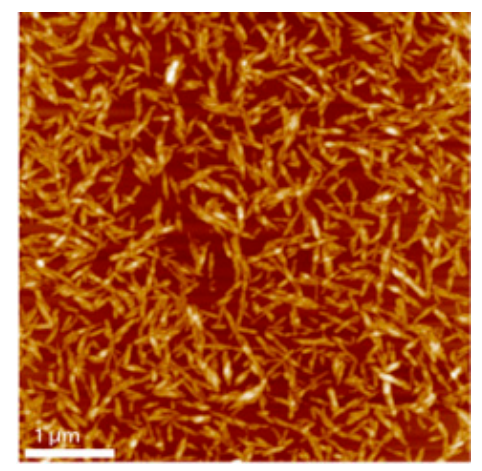

(c)

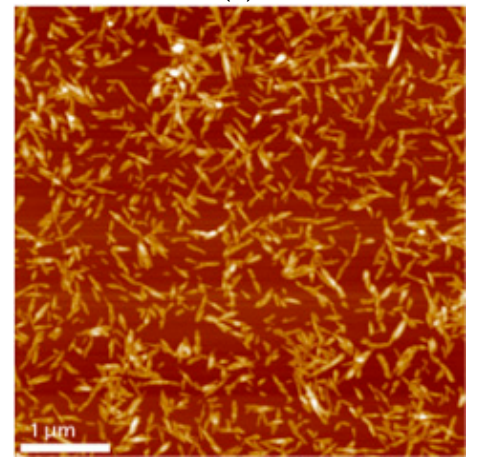

(f)

Figure 6. AFM images of cellulose nanocrystals after different hydrolysis conditions. (a) 50-30; (b) 50-45; (c) $50-60$ (d) 60-30; (e) 60-45; (f) 60-60.

The surface of selected elaborated membranes can be observed in Figure 7. The CNC-CHX coatings become evident exhibiting the homogeneity of the membranes with different concentrations of the drug and random orientation. The membrane preparation methodology used in this study favors a controlled release of the drug since the membrane is formed with the drug in contrast to other studies that put the drug at the ready vehicle. The AFM was also used for surface roughness determination; the changes in roughness have the expected behavior, as the amount of drug added reduces the roughness. The lower surface roughness (Table 3) of the samples CNC $+0.0015 \mathrm{~g} \mathrm{CHX}$ and $\mathrm{CNC}+0.00015 \mathrm{~g}$ CHX compared to the sample without drug (CNC) may be explained by the total dispersion of the dissolved drug in the cellulose solution.

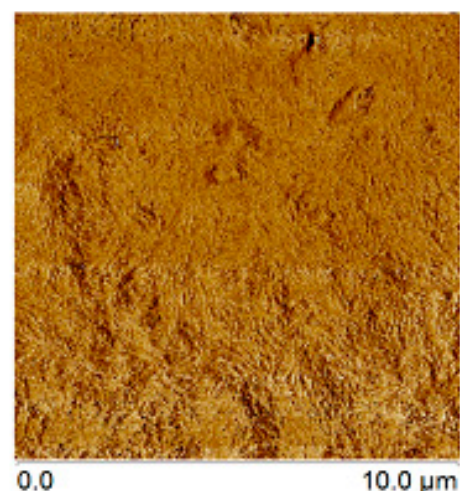

(a)

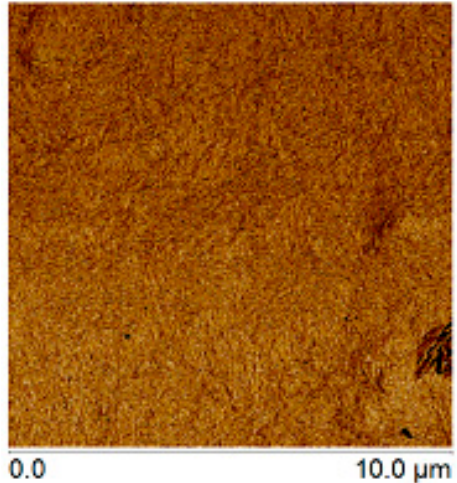

(b)

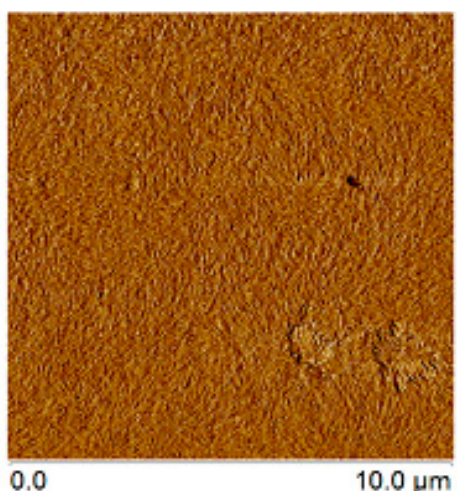

(c)

Figure 7. AFM images of CNC membranes + $0.015 \mathrm{~g} \mathrm{CHX} \mathrm{(a);} \mathrm{CNC} \mathrm{membranes} \mathrm{+} 0.0015 \mathrm{~g} \mathrm{CHX} \mathrm{(b);}$ and $\mathrm{CNC}$ membranes $+0.00015 \mathrm{~g} \mathrm{CHX} \mathrm{(c)} \mathrm{and} \mathrm{the} \mathrm{roughness} \mathrm{of} \mathrm{the} \mathrm{membranes.}$ 
Table 3. Root mean squared roughness (RMS) of the membranes.

\begin{tabular}{ccc}
\hline SAMPLES & RMS * \\
\cline { 2 - 3 } CNC + 0.015 g CHX & 44.85 \\
$\mathrm{CNC}+0.0015 \mathrm{~g} \mathrm{CHX}$ & 28 \\
$\mathrm{CNC}+0.0015 \mathrm{~g} \mathrm{CHX}$ & 5.87 \\
\cline { 2 - 2 } * Values were evaluated over an area of $25 \mathrm{~nm}^{2}$ at different locations.
\end{tabular}

\subsection{Drug Release}

Figure $8 \mathrm{~A}$ presents the drug release of the membranes as a function of time; results are similar for the three tested concentrations. For the evaluation of drug delivery, the drug was added to $\mathrm{CNC}$ solutions and taken to the oven for solidification; this may account for the delivery of CHX around $10 \%$. Literature reports that the mechanisms of adsorption of CHX onto cellulosic fibers appear to be controlled mainly by electrostatic forces between the cationic groups of the CHX and the carboxyl acid groups of cellulose fibers, as well as the hydrogen bonding between the biguanide group and the $p$-chlorophenol of the CHX with hydroxyl groups of cellulose [10].

Results demonstrate that the membrane could deliver the antimicrobial drug CHX with a satisfactory performance. The $\mathrm{CNC}$ solution proves to be a promising vehicle for drug delivery, considering that the drug is not inserted superficially in the membrane but rather dissolved and inserted during the preparation of the membrane, giving a stronger interaction than membranes which are immersed in the solution containing the drug.

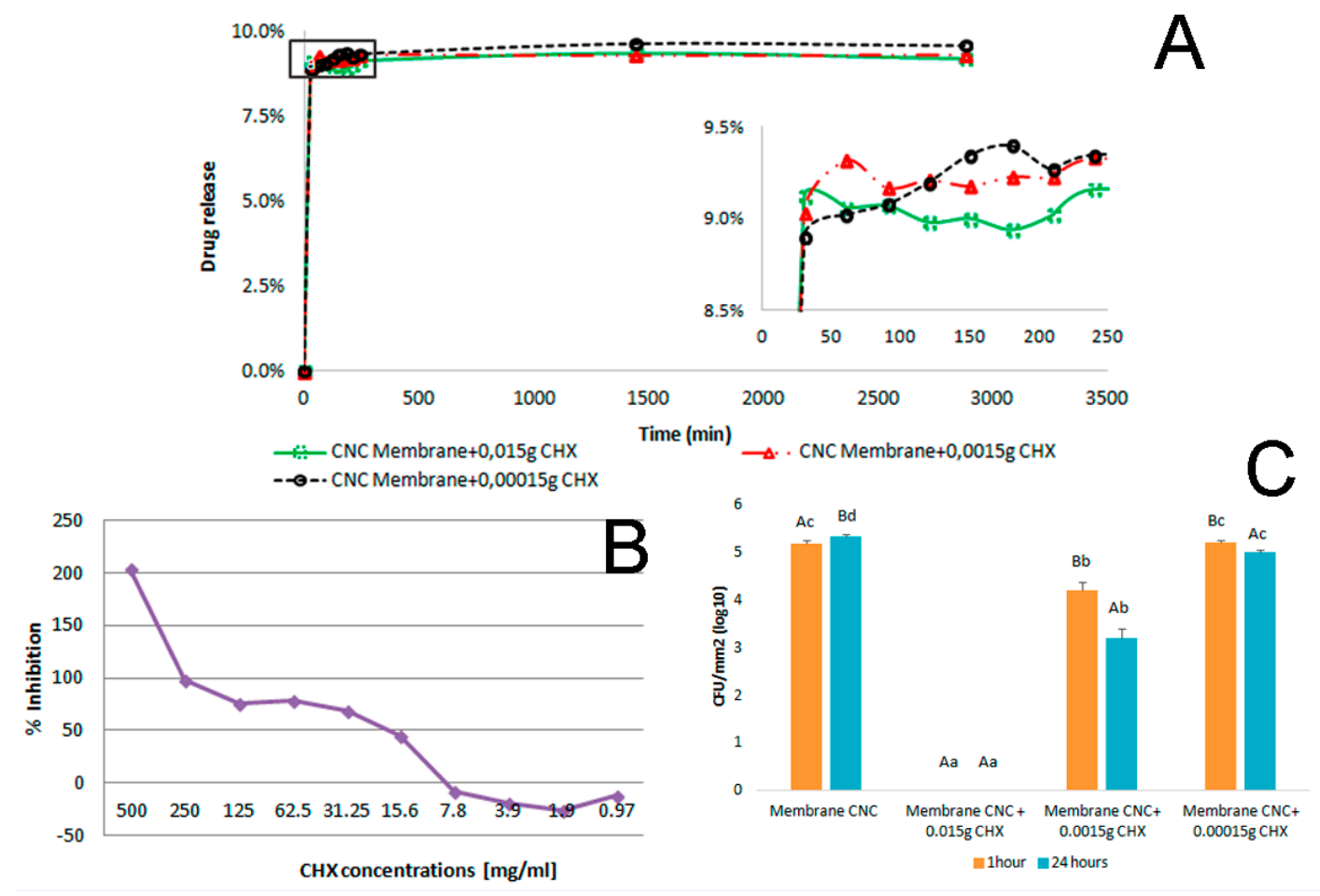

Figure 8. Membrane release profile from 0 to $48 \mathrm{~h}$ and highlights for the first $250 \mathrm{~min}$ (A); in vitro antibacterial activity of chlorhexidine dissolved in DMSO against $S$. aureus (B); survival of S. aureus ATCC 19095 after modified direct contact test. Different capital letters represent statistically significant differences in the group and different lower case letters represent statistically significant differences between groups $(p<0.05)(\mathbf{C})$. 


\subsection{Antibacterial Activity}

3.10.1. Minimum Inhibitory Concentration (MIC) and Minimum Bactericidal Concentration (MBC) of Chlorhexidine

Broth microdilution technique was chosen in order to determine the susceptibility of the selected microorganism to the antimicrobial agent studied. The results obtained for the minimum inhibitory concentration and minimum bactericidal concentration are shown in Figure 8B. The results show the MIC and MBC values (31.25 $\mathrm{mg} \cdot \mathrm{mL}^{-1}$ for S. aureus).

The data obtained suggest that the CHX was effective against $S$. aureus at even a $31.25 \mathrm{mg} \cdot \mathrm{mL}^{-1}$ concentration. As an expected behavior, the susceptibility of the microorganism varied according to the concentrations of the antimicrobial drugs agent. The inhibition against the microorganism was directly proportional to the concentration of chlorhexidine, constantly increasing as the concentration got higher than $31.25 \mathrm{mg} \cdot \mathrm{mL}^{-1}$.

\subsubsection{Modified Direct Contact Test (mDCT)}

The ability of CNC-CHX membranes to inhibit the growth or even kill S. aureus cultivars was evaluated. The CNC membrane without drugs was used as the control, and the inhibition results of S. aureus ATCC 19095 are presented in Figure 8C. The CNC membrane $+0.015 \mathrm{~g}$ CHX totally inhibited bacterial growth after $1 \mathrm{~h}$ and $24 \mathrm{~h}$. There was a proportionally direct decrease in the inhibition of the bacteria growth in accordance with the decrease in drug concentration. In high concentrations, $\mathrm{CHX}$ is bactericidal via destruction of the cell membrane. This can be explained because at lower concentrations, $\mathrm{CHX}$ has bacteriostatic properties [13].

\section{Conclusions}

CNCs were successfully obtained by high frequency cavitation induced acid hydrolysis. The analyses were performed to evaluate the characteristics of the particles, and the results showed that all times and temperatures tested are viable to obtain CNC without further treatments. This approach reduces the hydrolysis time by half compared with the conventional hydrolysis (without cavitation) and can be useful when morphology control of the CNC is an important aspect, and thus choice of conditions used in future works depends on the desired morphological features.

In this study, cellulose nanocrystals were applied in solution as excipient obtaining membranes charged with CHX. The methodology for obtaining the membranes proved to be simple and efficient. The results of release experiments showed that the nanocrystal membranes had sustained release properties and the release kinetics show that the quantities delivered are maintained over at least $48 \mathrm{~h}$ even with a low concentration of drugs, and this makes CNC membranes a potential candidate for drug delivery applications. The antibacterial activity of the CNC membrane with $0.015 \mathrm{~g}$ of CHX was found to be highly effective against $S$. aureus, showing that the CNC-CHX membranes can be used for antimicrobial applications.

In future work, in vitro cytotoxicity assays will be performed to assess the cell viability provided by the CNC-CHX membranes, and the behavior of other drugs also incorporated into CNC membranes will be studied in order to clarify the behavior and compare the membrane with other excipients.

Acknowledgments: The authors would like to acknowledge the Department of Education, Universities and Investigation of the Basque Government (project IT1008-16), the Federal Agency for Support and Evaluation of Graduate Education (CAPES) through process BEX 8710/14-7, the Mexican Council of Science and Technology (CONACyT) through scholarship 216178 and theBrazilian National Council for Scientific and Technological Development for financial support through CNPq (\# 482251/2013-1) for financially supporting this work. The authors also thank Maite Insausti and Oihane Arriortua for their kind help and support with Nanosizer and SGIker of the University of the Basque Country UPV/EHU for technical and human support provided with XRD, NMR and AFM characterizations and Altair Faes of the Regional Center of Oncology of the Federal University of Pelotas (UFPel) for the use of the equipment Eldorado 78. 
Author Contributions: A.M.B. and J.L. conceived and designed the experiments; E.R. and A.M.B. extracted the $\mathrm{CNC}$ and made the CNC membranes; JA.M.B. analyzed the drug release; J.S.R. and R.G.L. analyzed the antibacterial activity; A.M.B., E.R. and N.L.V.C. wrote the paper.

Conflicts of Interest: The authors declare no conflict of interest. The founding sponsors had no role in the design of the study; in the collection, analyses, or interpretation of data; in the writing of the manuscript, and in the decision to publish the results.

\section{References}

1. Alila, S.; Besbes, I.; Vilar, M.R.; Mutjé, P.; Boufi, S. Non-woody plants as raw materials for production of microfibrillated cellulose (MFC): A comparative study. Ind. Crops Prod. 2013, 41, 250-259. [CrossRef]

2. Bos, H.L.; Van den Oever, M.J.A.; Peters, O.C.J.J. Tensile and compressive properties of flax fibres for natural fibre reinforced composites. J. Mater. Sci. 2002, 37, 1683-1692. [CrossRef]

3. Jonoobi, M.; Oladi, R.; Davoudpour, Y.; Oksman, K.; Dufresne, A.; Hamzeh, Y.; Davodi, R. Different preparation methods and properties of nanostructurated cellulose from various natural resources and residues: A review. Cellulose 2015, 22, 935-969. [CrossRef]

4. Bondeson, D.; Mathew, A.; Oksman, K. Optimization of the isolation of nanocrystals from microcrystalline cellulose by acid hydrolysis. Cellulose 2006, 13, 171-180. [CrossRef]

5. Li, J.; Zhang, X.; Zhang, M.; Xiu, H.; He, H. Ultrasonic enhance acid hydrolysis selectivity of cellulose with $\mathrm{HCl}-\mathrm{FeCl}_{3}$ as catalyst. Carbohydr. Polym. 2015, 117, 917-922. [CrossRef] [PubMed]

6. Moriana, R.; Vilapana, F.; Karlsson, S.; Ribes, A. Correlation of chemical, structural and thermal properties of natural fibres for their sustainable exploitation. Carbohydr. Polym. 2014, 112, 422-431. [CrossRef] [PubMed]

7. Li, W.; Wang, R.; Liu, S. Nanocrystalline cellulose prepared from softwood kraft pulp via ultrasonic assisted acid hydrolysis. BioResources 2011, 6, 4271-4281.

8. Montes, S.; Azcune, I.; Cabañero, G.; Grande, H.-J.; Odriozola, I.; Labidi, J. Functionalization of Cellulose Nanocrystals in Choline Lactate Ionic Liquid. Materials 2016, 9, 499. [CrossRef]

9. Kolakovic, R.; Laaksonen, T.; Peltonen, L.; Laukkanen, A.; Hirvonen, J. Spraydried nanofibrillar cellulose microparticles for sustained drug release. Int. J. Pharm. 2012, 430, 44-55. [CrossRef] [PubMed]

10. Lavoine, N.; Desloges, I.; Sillard, C.; Bras, J. Controlled release and long-term antibacterial activity of chlorhexidine digluconate through the nanoporous network of microfibrillated cellulose. Cellulose 2014, 21, 4429-4442. [CrossRef]

11. Veeramachineni, A.K.; Sathasivam, T.; Muniyandy, S.; Janarthanan, P.; Langford, S.J.; Yan, L.Y. Optimizing Extraction of Cellulose and Synthesizing Pharmaceutical Grade Carboxymethyl Sago Cellulose from Malaysian Sago Pulp. Appl. Sci. 2016, 6, 170. [CrossRef]

12. Wang, C.; Huang, H.; Jia, M.; Jin, S.; Zhao, W.; Cha, R. Formulation and evaluation of nanocrystalline cellulose as a potential disintegrant. Carbohydr. Polym. 2015, 130, 275-279. [CrossRef] [PubMed]

13. Attin, T.; Abouassi, T.; Becker, K.; Wiegand, A.; Roos, M.; Attin, R. A new method for chlorhexidine (CHX) determination: $\mathrm{CHX}$ release after application of differently concentrated $\mathrm{CHX}$-containing preparations on artificial fissures. Clin. Oral Investig. 2008, 12, 189-196. [CrossRef] [PubMed]

14. Yerushalmi, S.M.; Buck, M.E.; Lynn, D.M.; Lemcoff, N.G.; Meijler, M.M. Multivalent Alteration of Quorum Sensing in Staphylococcus aureus. Chem. Commun. 2013, 49, 5177-5179. [CrossRef] [PubMed]

15. Robles, E.; Urruzola, I.; Labidi, J.; Serrano, L. Surface modified nano-cellulose as reinforcement in poly(lactic acid) to conform new composites. Ind. Crops Prod. 2015, 71, 44-53. [CrossRef]

16. Smoluchowski, M. Contribution to the theory of electro-osmosis and related phenomena. Bull. Int. Acad. Sci. Crac. 1903, 3, 184-199.

17. He, J.; Shizhong, C.; Wang, S. Preparation and crystalline analysis of high-grade bamboo dissolving pulp for cellulose acetate. J. Appl. Polym. Sci. 2008, 107, 1029-1038. [CrossRef]

18. Segal, L.; Creely, J.J.; Martin, A.E., Jr.; Conrad, C.M. An empirical method for estimating the degree of crystallinity of native cellulose using the X-ray diffractometer. Text. Res. J. 1959, 29, 786-794. [CrossRef]

19. French, A.D.; Santiago Cintrón, M. Cellulose polymorphy, crystallite size, and the Segal Crystallinity Index. Cellulose 2013, 20, 583-588. [CrossRef]

20. Park, S.; Baker, J.O.; Himmel, M.E.; Parilla, P.A.; Johnson, D.K. Cellulose crystallinity index: Measurement techniques and their impact on interpreting cellulose performance. Biotechnol. Biofuels 2010, 3, 10. [CrossRef] [PubMed] 
21. Urruzola, I.; Robles, E.; Serrano, L.; Labidi, J. Nanopaper from almond (Prunus dulcis) shell. Cellulose 2014, 21, 1619-1629. [CrossRef]

22. Hult, E.L.; Iversen, T.; Sugiyama, J. Characterization of the supermolecular structure of cellulose in wood pulp fibres. Cellulose 2003, 10, 103-110. [CrossRef]

23. Terinte, N.; Ibbett, R.; Schuster, K.C. Overview on native cellulose and microcrystalline cellulose I structure studied by X-ray diffraction (WAXD): Comparison between measurement techniques. Lenzing. Ber. 2011, 89, 118-131.

24. Scherrer, P. Bestimmung der Größe und der inneren Struktur von Kolloidteilchen mittels Röntgenstrahlen. Nachr. Ges. Wiss. Gött. Math.-Phys. Kl. 1918, 1918, 98-100.

25. Warren, B.E. X-ray Diffraction; Addison-Wesley Pub. Co.: Reading, MA, USA, 1969.

26. Pfaller, M.A.; Messer, S.A.; Coffman, S. Comparison of visual and spectrophotometric methods of MIC endpoint determinations by using broth microdilution methods to test five antifungal agents, including the new triazole D0870. J. Clin. Microbiol. 1995, 33, 1094-1097. [PubMed]

27. Felício, R.; Albuquerque, S.; Young, M.C.M.; Yokoya, N.S.; Debonsi, H.M. Trypanocidal, leishmanicidal and antifungal potential from marine red alga Bostrychia tenella J. Agardh (Rhodomelaceae, Ceramiales). J. Pharm. Biomed. Anal. 2008, 52, 763-769. [CrossRef] [PubMed]

28. Zhang, H.; Shen, Y.; Ruse, N.D.; Haapasalo, M. Antibacterial Activity of Endodontic Sealers by Modified Direct Contact Test against Enterococcus Faecalis. J. Endod. 2009, 35, 1051-1055. [CrossRef] [PubMed]

29. Abdul Khalil, H.P.S.; Rozman, H.D.; Ahmad, M.N.; Ismail, H. Acetylated Plant-Fiberreinforced Polyester Composites: A Study of Mechanical, Hygrothermal, and Aging Characteristics. Polym.-Plast. Technol. 2000, 39, 757-781. [CrossRef]

30. Thygesen, A.; Madsen, B.; Bjerre, A.B.; Lilholt, H. Cellulosic Fibers: Effect of Processing on Fiber Bundle Strength. J. Nat. Fibers 2011, 8, 161-175. [CrossRef]

31. Sun, X.F.; Sun, R.C.; Fowler, P.; Baird, M.S. Isolation and characterization of cellulose obtained by a two-stage treatment with organosolv and cyanamide activated hydrogen peroxide from wheat straw. Carbohydr. Polym. 2004, 55, 379-391. [CrossRef]

32. Buschle-Diller, G.; Inglesby, M.K.; Wu, Y. Physicochemical properties of chemically and enzymatically modified cellulosic surfaces. Colloids Surf. A 2005, 260, 63-70. [CrossRef]

33. Revol, J.F.; Bradford, H.; Giasson, J.; Marchessault, R.H.; Gray, D.G. Helicoidal self-ordering of cellulose microfibrils in aqueous suspension. Int. J. Biol. Macromol. 1992, 14, 170-172. [CrossRef]

34. Gast, J.C.; Atalla, R.H.; McKelvey, R.D. The ${ }^{13}$ C-n.m.r. spectra of the xylo- and cello-oligosaccharides. Carbohydr. Res. 1980, 84, 137-146. [CrossRef]

35. French, A.D. Idealized powder diffraction patterns for cellulose polymorphs. Cellulose 2014, 212, 885-896. [CrossRef]

36. Yu, H.Y.; Qin, Z.Y.; Liu, L.; Yang, X.G.; Zhou, Y.; Yao, J.M. Comparison of the reinforcing effects for cellulose nanocrystals obtained by sulfuric and hydrochloric acid hydrolysis on the mechanical and thermal properties of bacterial polyester. Compos. Sci. Technol. 2013, 87, 22-28. [CrossRef]

(c) 2016 by the authors; licensee MDPI, Basel, Switzerland. This article is an open access article distributed under the terms and conditions of the Creative Commons Attribution (CC-BY) license (http://creativecommons.org/licenses/by/4.0/). 